Journal of Animal and Veterinary Advances 11 (11): 1847-1852, 2012

ISSN: $1680-5593$

(C) Medwell Journals, 2012

\title{
Study of a Simple and Rapid PCR Sex Identification of Bovine Embryo
}

\author{
${ }^{1}$ Huabin Zhu, ${ }^{1}$ Bo Lin, ${ }^{3}$ Jun Chen, ${ }^{1}$ Haisheng Hao, ${ }^{1}$ Xueming Zhao, ${ }^{2}$ Shujing Li, \\ ${ }^{1}$ Weihua Du, ${ }^{1}$ Tong Qin, ${ }^{1}$ Yan Liu and ${ }^{1}$ Dong Wang \\ ${ }^{1}$ The Key Laboratory for Farm Animal Genetic Resources and Utilization, \\ Chinese Academy of Agricultural Sciences, Ministry of Agriculture of China, \\ Institute of Animal Sciences, 100193 Beijing, China \\ ${ }^{2}$ Beijing Anbo Embryo Biotech Centre, 100193 Beijing, China \\ ${ }^{3}$ Department of Biostatistics, School of Public Health and Tropical Medicine, \\ Tulane University, New Orleans, 70112 LA, USA
}

\begin{abstract}
A rapid and simple PCR sex identification of embryo is very important for bovine embryo transferring. Many sex identification methods using duplex PCR were established according to Sry gene. But the identification process was affected greatly by more primers interaction. In order to decrease the interference from more primers, researchers explored a simple and rapid PCR Method. The sequences of Amelogenin alleles located at both sex chromosomes were downloaded from GenBank. A pair of sex specific primers was designed to span the $63 \mathrm{bp}$ longer insertion sequence in $\mathrm{X}$ chromosome. Bovine samples of blood, fibroblasts and demiembryos were sexed with these primers. Two-temperature PCR cycling program was used in which the extension step was deleted while the denaturizing and annealing steps were shortened to $1 \mathrm{sec}$. The results shown ideal identification were obtained and observable amplification were also obtained using even single fibroblast. About 20 bovine embryos were identified by this PCR cycling program and 15 embryos ( 9 females and 6 males) were transferred. The sexing results were confirmed by the anatomically proven sex after parturition, respectively. The comparison of amplification results between blood samples of bovine and human shows the excellent, specificity to bovine. Thus, a simple, rapid and effective PCR sex identification method was established.
\end{abstract}

Key words: Bovine embryo, rapid PCR, sex identification, simple PCR, sex chromosome, China

\section{INTRODUCTION}

Sex identification for the pre-implanting embryos plays a very important role in commercial husbandry production and animal breeding (Mapletoft and Hasler, 2005; Chandler et al., 2007). The current studies focus on establishing fast, sensitive sex identification method using PCR with low cost, some methods were established and extensively used (Tominaga and Hamada, 2004; Fu et al., 2007; Lu et al., 2007; Akyuz et al., 2010). Comparing with PCR methods based on Sry sequence specific to $\mathrm{Y}$ chromosome, the nest PCR and preamplification were applied during duplex PCR using a pair of internal primers. The interaction among primers was strengthened during the duplex PCR procedure and products from non-specific amplification such as primer bands were inevitable. The efficiency and quantity of specific amplification were also lowered (Phua et al., 2003;
Liguori et al., 2007). In some situations, it is difficult to determine, quickly and exactly, the embryo sex using the methods above. There are other sex specific sequences such as Amelogenin and $\mathrm{ZfX} / \mathrm{Zfy}$, locating at both $\mathrm{X}$ and $\mathrm{Y}$ chromosomes but displaying different polymorphism between two sex chromosomes, this is different from Sry sequence. If these sequences were used to design primers for the sex identification, the amplication result should be different from the strategy based on Sry sequence. PCR products for both sex chromosomes can be obtained at each PCR amplification with this kind of sex specific primers. Because internal primers are not needed any more in this detection strategy, the interaction among primers is lowered maximally. Although, better identification results were obtained with this detecting strategy in some studies, separately the detection time is still long and the operation process is tedious (Aasen and Medrano, 1990; Chen et al., 1999; Shadrach et al., 2004).

Corresponding Author: Dong Wang, The Key Laboratory for Farm Animal Genetic Resources and Utilization, Chinese Academy of Agricultural Sciences, Ministry of Agriculture of China, Institute of Animal Sciences, 100193 Beijing, P.R. China 
In present study, the sequence alignment of Amelogenin alleles in different sex chromosome was applied and a pair of sex specific primers was designed to span the longer deletion fragment in $\mathrm{Y}$ chromosome. In order to reduce the amplification time, the extension step of PCR temperature cycle program was deleted (Wang et al., 2011) and the steps for annealing and denaturation were shortened. Thus, the sex of bovine embryos was identified with this two-temperature PCR.

\section{MATERIALS AND METHODS}

Materials collection and preparation: The DNA templates were prepared from the blood samples of male and female Holstein and those of man and women presented by Hospital of Chinese Agricultural University. The $100 \mu \mathrm{L}$ of anticoagulant blood was fully mixed with $900 \mu \mathrm{L}$ of $\mathrm{ddH}_{2} \mathrm{O}$. The mixture was centrifuged at $12,000 \mathrm{rpm}$ for $1 \mathrm{~min}$. The supernatant was discarded and the pellet was washed once with $\mathrm{ddH}_{2} \mathrm{O}$ then mixed with $100 \mu \mathrm{L}$ of $\mathrm{ddH}_{2} \mathrm{O}$ and boiled for $10 \mathrm{~min}$. This mixture was cooled on ice for $5 \mathrm{~min}$ and re-centrifuged for $5 \mathrm{~min}$. The supernatant was extracted. The DNA was either used immediately for $\mathrm{PCR}$ reaction or stored at $-20^{\circ} \mathrm{C}$ for future use.

Centrifuge the fibroblast to collect the cell pellet then wash the cell pellet with PBS and adjust the fibroblast cell to $1 \times 10^{3}$ cell $\mathrm{mL}^{-1}$ and separate the fibroblast with suction pipe in 1,5 and 10 cells each time, put the separated fibroblast in different centrifuge tube and marked with cell number, respectively for sex identification experiment.

Micromanipulation of embryo: The Holstein embryos were recovered from the genitor tracts of super ovulated female donors after $6 \sim 7$ days of mating. The embryo was transferred individually to $100 \mu \mathrm{L}$ droplets of Splitting Medium without Bovine Serum Albumin (BSA) and was split into demi-embryos and used to check the efficiency of the simple PCR method setup, also 3 10 blastomeres were sampled from each embryo for sex identifying before embryo transfer. The biopsy samples were transferred into a $0.2 \mathrm{~mL}$ PCR tube and marked with the embryo number then stored at $-20^{\circ} \mathrm{C}$ until analysis or detected at once.

The alignment between two alleles sequence and the primer design: In order to study the polymorphism of the Amelogenin Gene ( $A M L$ ) between two alleles in different sex chromosomes, the gene sequences were downloaded from GenBank. Two long sequences of amelogenin gene, $A M E L Y$ and $A M E L X$ were selected. The DNA sequence of AMELY gene (GenBank No.: AB091790.1) is 6264 bp long and that of AMELX (GenBank No.: AB091789.1) is
$6451 \mathrm{bp}$ long. The sequence alignment of AMELX and AMELY was performed with the DNAMAN Software. According to the sequence alignment, a pair of sex specific primers AML395 was designed with Oligo 6.0 Software to span the longer insertion sequence on $\mathrm{X}$ chromosome. The primer sequences are showed as follows the forward primer AML395F: 5'- TTCTCACC AGTACCCTTCCTA-3'; the reverse primer AML395R: 5'TCAGAGGCAGGTCAG GAAGCA-3'. The PCR product of female bovine sample is $458 \mathrm{bp}$ long and male product is 395 bp long. The primers were synthesized by Invitrogen (Shanghai, China).

Construction of the rapid PCR sex identification method: A $20 \mu \mathrm{L}$ of PCR amplification reaction was performed including $2 \mu \mathrm{L}$ of DNA template cooked from blood sample, $0.6 \mu \mathrm{L}$ of $2.5 \mathrm{U} \mu \mathrm{L}^{-1}$ TaqDNA polymerase, $4 \mu \mathrm{L}$ of $2 \mu \mathrm{mol} \mu \mathrm{L}^{-1}$ primer AML $395,4 \mu \mathrm{L}$ of $1 \mathrm{mmol} \mathrm{L}^{-1} \mathrm{dNTP}$, $2 \mu \mathrm{L}$ of $10 \times$ PCR buffer and $7.4 \mu \mathrm{L}$ of $\mathrm{ddH}_{2} \mathrm{O}$. A rapid PCR thermal cycle program was used that was established before by the study group and the program was processed as followed: preheating at $94^{\circ} \mathrm{C}$ for $5 \mathrm{~min}$, 30 cycles $94^{\circ} \mathrm{C}$ for $1 \mathrm{sec}$ and $55^{\circ} \mathrm{C}$ for $1 \mathrm{sec}$, finally, extending at $72^{\circ} \mathrm{C}$ for $6 \mathrm{~min}$. The amplification time was recorded at once. The PCR products were preserved in $4^{\circ} \mathrm{C}$ or detected with agarose gel electrophoresis.

The feasibility and the sensitivity of this PCR Method were also detected with fibroblast samples with different cell number. The $2 \mu \mathrm{L}$ of blood DNA template in above PCR protocol were replaced by certain number of fibroblast, the same PCR thermal cycle program was used and optimized at the same time. After the amplification effect of sex specific primer AML395 was proved using fibroblast and demi-embryo, the optimized amplification system was used to identify the embryo sex and the specificity of this pair of primers to species was detected using human and bovine blood samples.

\section{RESULTS AND DISCUSSION}

The sequence alignment result between two $A M L$ alleles: The alignment result showed that there is a 63 bp length deletion in $A M L Y$ gene in the site from 6254-6316 bp in $A M L X$ gene sequence. For the two alleles are located at different sex chromosomes, these two alleles can be amplified at the same time, the length polymorphism of the alleles can be detected through agarose gel electrophoresis. So, the primers spanning the deletion were designed according to the alignment result in $A M L Y$ gene sequence and were marked in red color. The former primer was located from 5853-5873 bp and the reverse primer was located from $6227-6247 \mathrm{bp}$ (Fig. 1). 
The sex identification result of bovine blood DNA template using rapid PCR: After amplification with primer AML395, the PCR products were detected through $2 \%$ agarose gel electrophoresis. The electrophoresis result shown in Fig. 2 indicated clear and bright bands obtained in each individual. All female individuals displayed a 458 bp long band specific to $\mathrm{X}$ chromosome while all male individuals displayed not only a 458 bp X chromosome specific band but also a 395 bp long band specific to $\mathrm{Y}$ chromosome and the detected results of all blood samples were consistent with known gender of all individual. The total amplification time is $48 \mathrm{~min}$.

The sex identification of bovine fibroblast using rapid PCR: After the ideal result of sex identification from blood samples was obtained with primer AML395, the sensitivity and the feasibility of this rapid PCR Method was detected in fibroblast in different cell number gradient. In order to further shorten the amplification time, the thermal cycle parameters were optimized also and the optimized parameters were $94^{\circ} \mathrm{C}$ for $30 \mathrm{sec}$ followed by 30 cycles of $94^{\circ} \mathrm{C}$ for $1 \mathrm{sec}, 55^{\circ} \mathrm{C}$ for $1 \mathrm{sec}$ and then a $1 \mathrm{~min}$ extension at $72^{\circ} \mathrm{C}$. The amplification results were shown in Fig. 3. Clear, bright and sex specific PCR products were obtained from all fibroblast samples and there was not any difference among all samples with different cell number. The sex determination results of all fibroblast samples were consistent with the known gender of samples completely. Furthermore, it cost only 38 min to complete the whole PCR amplification process.
The sex identification of bovine embryos using rapid PCR: For further proving this rapid PCR Method, 4 embryos were split into two demi-embryos and both of demi-embryos were detected at the same time. The detected result in Fig. 4 showed that all embryo samples displayed as clear and bright bands as detected in blood and fibroblast samples and the same sex identification result was also obtained from both demi-embryo samples. Then, 20 embryos were sexed with this simple and rapid sex identification method and 6 male embryos and all 9 female embryos were transferred into 15 recipient cows and 10 calves were born ( $66.7 \%$ calving rate) of which 7 were females and 3 were males. Figure 5 shows the sexing results of the embryos after agarose gel electrophoresis. The sexing results were completely confirmed by the anatomically proven sex after parturition, respectively.

The specificity of the sex identification method of bovine: In order to eliminate misgivings of the genetic material contamination from operator during sex determination, human blood samples from both man and women were detected by this identification system together with bovine blood samples. The detected result in Fig. 6 showed that 458 and 395 bp target DNA bands were only detected in cow and bull samples, respectively while not in woman and man blood samples. The detecting results implied that no specific amplification results could be obtain from human genetic materials when the sex identification system was performed and it is not necessary to worry about the contamination from operator during detection.

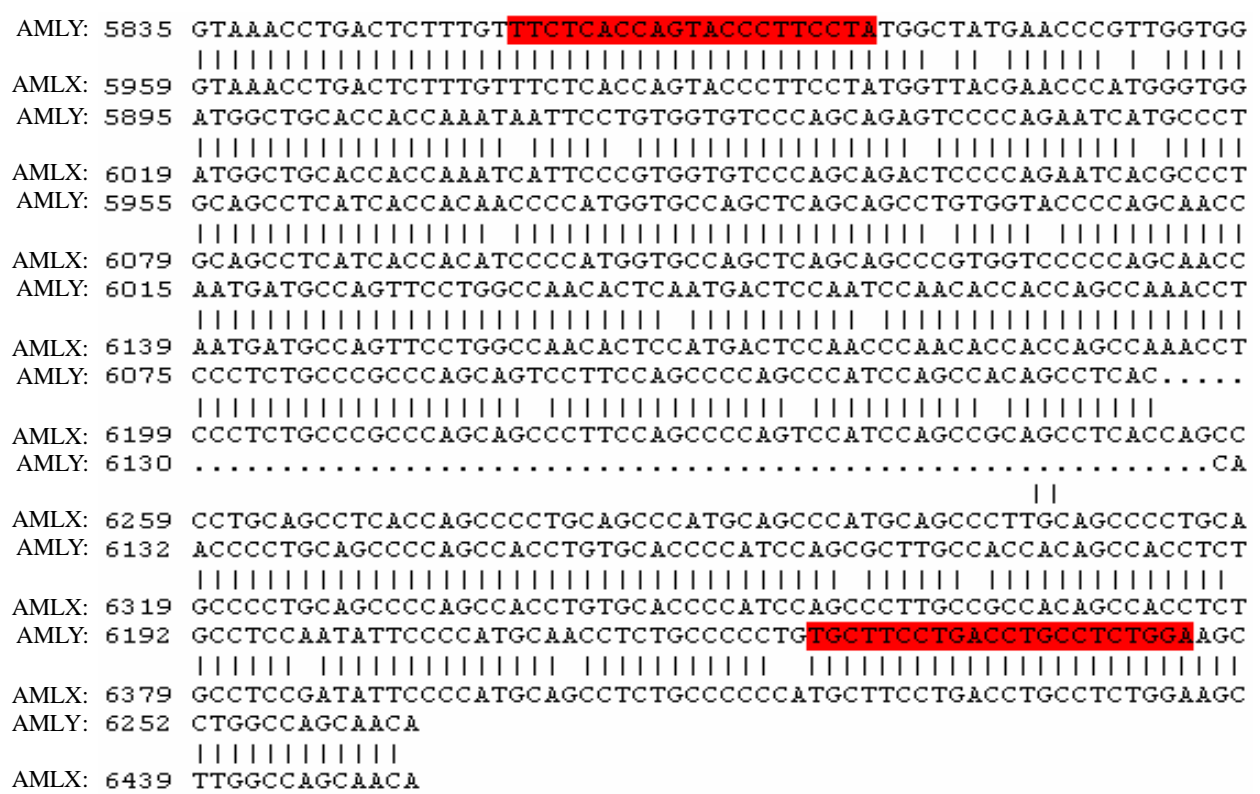

Fig. 1: The alignment result of partial sequences of AML alleles 


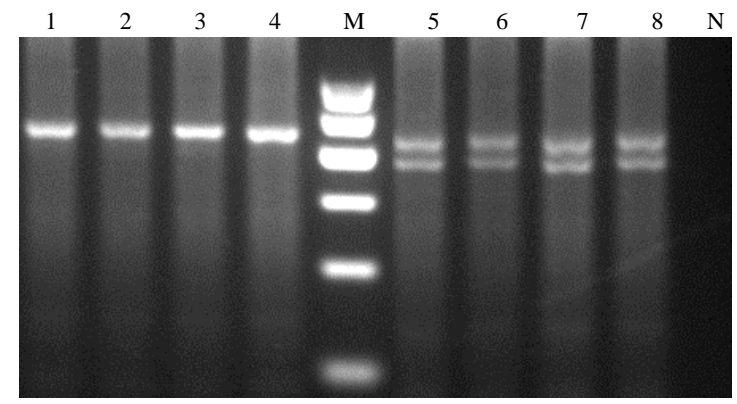

Fig. 2: The PCR amplification results of blood DNA samples from different bulls and cows. 1 4: The PCR products of 4 cows blood samples; 5 8: The PCR products of 4 bulls blood samples; N: Negative control; M: Molecular Marker I

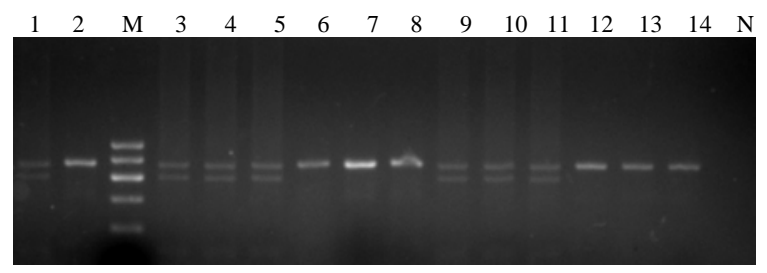

Fig. 3: The sex determination results of fibroblast using simple and rapid PCR Lane 1 and 2: bull and cow blood samples, respectively, M: Molecular Marker I, Lane 3 8: one cell, Lane 9 14: five cells. Lane 3 5 and 9 11: male fibroblast, Lane $6 \sim 8$ and 12 14: female fibroblast and N: Negative control

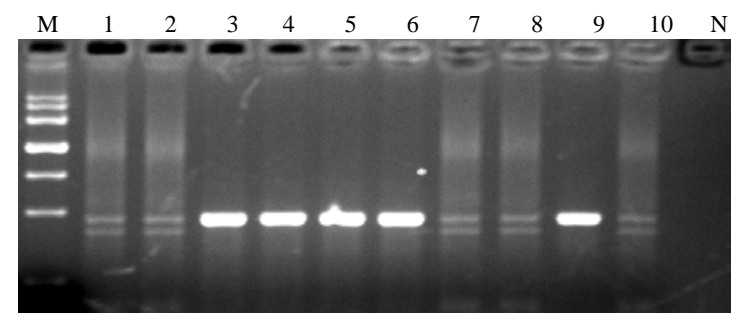

Fig. 4: The sex determination result of demi-embryo samples using simple and rapid PCR. Lane 1 and 2 are for two demi-embryo of embryo 1, Lane 3 and 4: two demi-embryo of embryo 2, Lane 5 and 6: two demi-embryo of embryo 3, Lane 7 and 8: two demi-embryo of embryo 4, Lane 9 and 10: female and male blood DNA samples, respectively, $\mathrm{N}$ : Negative control and M: Molecular Marker III $(4500 \backslash 3000 \backslash 2000 \backslash 1200 \backslash 800 \backslash 500 \backslash 200)$

In order to decrease the stress reaction of the embryo outside the body and increase the detecting efficiency, the establishment of the rapid and simple PCR

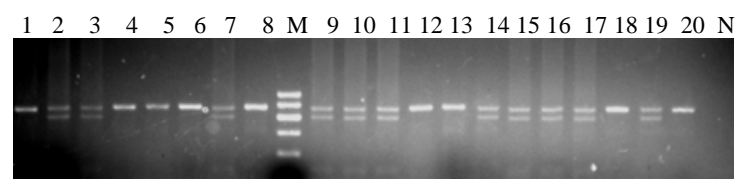

Fig. 5: The sex identification result of bovine embryo using simple and rapid PCR. Lane $1,4 \sim 6,8,12,13$, 18 and 20 were predicted as female which displayed only one $458 \mathrm{bp}$ band specific to $\mathrm{X}$ chromosome, Lane 2, 3, 7,9 11, 14 17 and 19 were predicted as male which displayed both sex chromosome specific bands. N: Negative control and M: Molecular Marker I

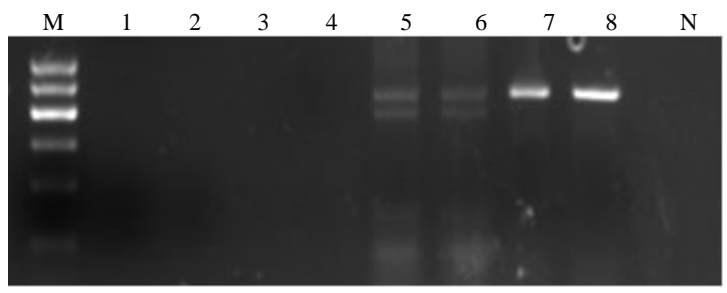

Fig. 6: The specificity comparison of this detection system between bovine and human blood samples. Lane 1 and 2 for man, lane 3 and 4 for woman, Lane 5 and 6 for bulls, 7 and 8 for cow, N: Negative control, M: Molecular Marker I

sex identification method was always focused on. However, the detecting time and the efficiency are always contrary. Lower template sampled from the embryo limits the PCR sexing identification. To increase the detection efficiency, a lot of PCR methods were established. Some studies spent $>2 \mathrm{~h}$ to finish the sex identification PCR after the DNA template was prepared with PEP-PCR (Tominaga and Hamada, 2004) while other studies spent even more times to get the PCR amplification (Pomp et al., 1995; Lu et al., 2007; Fu et al., 2007; Akyuz et al., 2010). Duplex PCR was used in all the current sex identification methods the amplification difficulty for the lower quantitative template was increased by the interaction among more primers. In the study, researchers used only one pair of primers to identify the embryo sex. The identification efficiency is increased greatly through lowering the interaction among primers and the ideal amplification results were obtained.

The parameter of PCR cycle program is another limitation factor to PCR sexing identification. There are three temperature steps in each cycle of common PCR program and about $30 \mathrm{sec}$ or even more time was used in each temperature step when common PCR program was used before. The amplification efficiency and specificity however were increased when the transitions between 
temperatures and individual periods of denaturizing, annealing and extension were shortened (Wittwer et al., 1990; Cha et al., 1992; Eggerding, 1995). Some studies already obtained better amplification by decreasing the transition time between every temperature steps and the periods of each step (Welch and Johnson, 1999; Welch et al., 1995). In this study, each cycle step was shortened to $1 \mathrm{sec}$ and the extension step was deleted. As a result, not only the amplification efficiency and specificity were improved but the total amplification time was also shortened to $38 \mathrm{~min}$.

The sensitivity is the third determinant to PCR sexing identification. To improve the sensitivity, the PEP-PCR and nest PCR Method were established (Tominaga and Hamada, 2004; Fu et al., 2007) the tedious operation lengthened the amplification time and increased the chance of contamination. In the study, the sensitivity is improved using this simple and rapid cycling program with only one pair of primers. The ideal identification results were obtained even with single cells and both gender-specific and gender-neutral signals can be obtained at the single PCR process using this method.

\section{CONCLUSION}

A rapid, simple, efficient method was established for bovine embryo sex identification, no internal control is required any more. The amplification process only takes $38 \mathrm{~min}$ and is sensitive enough even with single cell. This rapid PCR Method is efficient in time and money and might be meaningful to many fields such as forensic medicine, clinical medicine and sex identification.

\section{ACKNOWLEDGEMENTS}

This research was supported by the National Natural Science Foundation of China (No.: 30671502), the National $863 \mathrm{Hi}-\mathrm{Tech}$ Research and Development Program of China (No.: 2006AA10Z143 and No.: 2008AA101004) and National Science and Technology Support Program of China (No.: 2011BAD19B02). Jun Chen, Bo Lin and Huabin Zhu contributed equally to the study.

\section{REFERENCES}

Aasen, E. and J.F. Medrano, 1990. Amplification of the $\mathrm{ZFY}$ and ZFX genes for sex identification in humans, cattle, sheep and goats. Biotechnology, 8: 1279-1281.

Akyuz, B., O. Ertugrul, M. Kaymaz, H.C. Macun and D. Bayram, 2010. The effectiveness of gender determination using polymerase chain reaction and radioimmunoassay methods in cattle. Theriogenology, 73: 261-266.
Cha, R.S., H. Zarbl, P. Keohavong and W.G. Thilly, 1992. Mismatch Amplification Mutation Assay (MAMA): Application to the c-H-ras gene. Genome Res., 2: 14-20.

Chandler, J.E., T.M. Taylor, A.L. Canal, R.K. Cooper and E.B. Moser et al., 2007. Calving sex ratio as related to the predicted Y-chromosome-bearing spermatozoa ratio in bull ejaculates. Theriogenology, 67: 563-571.

Chen, C.M., C.L. Hu, C.H. Wang, C.M. Hung, H.K. Wu, K.B. Choo and W.T. Cheng, 1999. Gender determination in single bovine blastomeres by polymerase chain reaction amplification of sexspecific polymorphic fragments in the amelogenin gene. Mol. Reprod. Dev., 54: 209-214.

Eggerding, F.A., 1995. A one-step coupled amplification and oligonucleotide ligation procedure for multiplex genetic typing. Genome Res., 4: 337-345.

$\mathrm{Fu}, \quad$ Q., M. Zhang, W.S. Qin, Y.Q. Lu and H.Y. Zheng et al., 2007. Cloning the swamp buffalo SRY gene for embryo sexing with multiplex-nested PCR. Theriogenology, 68: 1211-1218.

Liguori, G., A. Lucariello, G. Colella, A. de Luca and P. Marinelli, 2007. Rapid identification of Candida species in oral rinse solutions by PCR. J. Clin. Pathol., 60: 1035-1039.

Lu, W., N. Rawlings, J. Zhao and H. Wang, 2007. Amplification and application of the HMG box of bovine SRY gene for sex determination. Anim. Reprod. Sci., 100: 186-191.

Mapletoft, R.J. and J.F. Hasler, 2005. Assisted reproductive technologies in cattle: A review. Rev. Sci. Tech. Off. Int. Epiz., 24: 393-403.

Phua, A.C.Y., R.B. Abdullah and M. Zulqarnain, 2003. A PCR-based sex determination method for possible application in caprine gender selection by simultaneous amplification of the $S r y$ and $A m l-X$ genes. J. Reprod. Dev., 49: 307-311.

Pomp, D., B.A. Good, R.D. Geisert, C.J. Corbin and A.J. Conley, 1995. Sex identification in mammals with polymerase chain reaction and its use to examine sex effects on diameter of day-10 or -11 pig embryos. J. Anim. Sci., 5: 1408-1415.

Shadrach, B., M. Commane, C. Hren and I. Warshawsky, 2004. A rare mutation in the primer binding region of the amelogenin gene can interfere with gender identification. J. Mol. Diagn., 6: 401-405.

Tominaga, K. and Y. Hamada, 2004. Efficient production of sex-identified and cryosurvived bovine in vitro produced blastocysts. Theriogenology, 61: 1181-1191. 
Wang, D., B. Lin, H. Zhu, H. Hao, C. Wu, W. Du and X. Zhao, 2011. Study of the amplification capacity of a two-temperature PCR and its application in bovine sex identification. J. Anim. Vet. Adv., 10: 715-722.

Welch, G.R. and L.A. Johnson, 1999. Sex preselection: Laboratory validation of the sperm sex ratio of flow sorted X- and Y-sperm by sort reanalysis for DNA. Theriogenology, 52: 1343-1352.
Welch, G.R., G.C. Waldbieser, R.J. Wall and L.A. Johnson, 1995. Flow cytometric sperm sorting and PCR to confirm separation of $\mathrm{X}$ - and $\mathrm{Y}$-chromosome bearing bovine sperm. Anim. Biotechnol., 6: 131-139.

Wittwer, C.T., G.C. Fillmore and D.J. Garling, 1990. Minimizing the time required for DNA amplification by efficient heat transfer to small samples. Anal. Biochem., 186: 328-331. 